\title{
МОДЕЛЮВАННЯ РУХУ АНТРОПОМОРФНОГО КРОКУЮЧОГО АПАРАТА НА ДОВІЛЬНІЙ ТВЕРДІЙ ПОВЕРХНІ
}

\begin{abstract}
Анотація: Моделювання ходи антропоморфного крокуючого апарата без зіткнення з поверхнею під час переміщення схилом чи підйомом, для задачі побудови крокуючих системи на основі антропного принципу.

Ключові слова: антропоморфний крокуючий апарат; закон руху; задача динаміки; регулятор рівноваги; довільна поверхня руху; вектор стану системи; складний багатоланковий апарат; кінематична схема; система керування; енергоефективність; фази руху.
\end{abstract}

\section{Вступ}

У стані економічного спаду, що переживае на сьогодні Україна, виникає потреба у збільшенні продуктивності праці з одночасним скороченням витрат на підготовку середовища. Особливо актуальним це питання постає у галузі видобування ресурсів, де часто виникає проблема забезпечення прохідності транспортних засобів. Перспективними, з точки зору прохідності, $є$ крокуючі апарати, але побудова транспортних засобів на їх основі має ряд труднощів, зокрема - низька енергоефективність та висока складність керування, що пов'язано з потребою формалізованого опису руху апарата на неоднорідній поверхні.

\section{Постановка задачі}

На сьогодні існуе багато моделей руху крокуючих апаратів, що описують їх переміщення на однорідних поверхнях. Найбільш точні моделі описують крокуючий апарат як об'єкт з антропним принципом руху $[1,4]$. Однак, подібна формалізація супроводжуеться ускладненням моделі та появою інваріантності у методах та моделях керування. Тому, з метою математичної наглядності, в більшості наукових праць розглядаються спрощені моделі руху, у яких процес руху та опис антропоморфного крокуючого апарата (АКА) здійснюеться методами активної динаміки [2], які враховують роботу приводів та вплив гравітації як негативної складової керування. Очевидно, що такі моделі мають низьку енергоефективність, що суттєво впливає на можливість практичного їх застосування. У зв'язку з цим, виникає потреба використання зовнішніх сил, що діють на АКА, як ефективної складової керування. Але методика керування АКА, в цьому випадку, описана не у повній мірі $[2,3,5,6]$. Так, залишаються не вирішеними задачі керування рухом АКА по похилій або неоднорідній поверхні та забезпечення його стійкості.

(c) М.М. Ткач, Д.О. Гуменний, Н.О. Якуніна, 2012 


\section{Формалізація руху АКА на неоднорідній поверхні}

В момент зіткнення АКА зазнае колізії у керуванні, що може призвести до порушення циклу його руху або втрати рівноваги. Одним з можливих методів мінімізації впливу даного фрактору на систему керування АКА є розробка додаткового регулятора, на базі моделі керування, для випадків переміщення неоднорідною поверхнею, який синтезовано за принципом мінімального відхилення від номінальних параметрів закону руху АКА. Спостереження зміни стану визначаеться за принципом порушення “комфортності” переміщення АКА впродовж циклу руху.

Як відомо [1], рух АКА є циклічним і складаеться з декількох фаз. Перша фаза (початкова) розпочинаеться з стану спокою (рис. 1, a), і характеризуеться двоопорною стійкістю (ДС) АКА. При цьому, проекція центру мас співпадає з поверхнею, яка визначаеться контуром опор АКА. При цьому, проекція центру мас співпадає з поверхнею, яка визначається контуром опор АКА. Наступна фраза характеризуеться одноопорною стійкістю АКА (рис. 1, b, d) коли проекція центру мас зміщуеться вздовж напрямку його руху і співпадає з проекцією розвантаженої опори на поверхню переміщення (ПП).
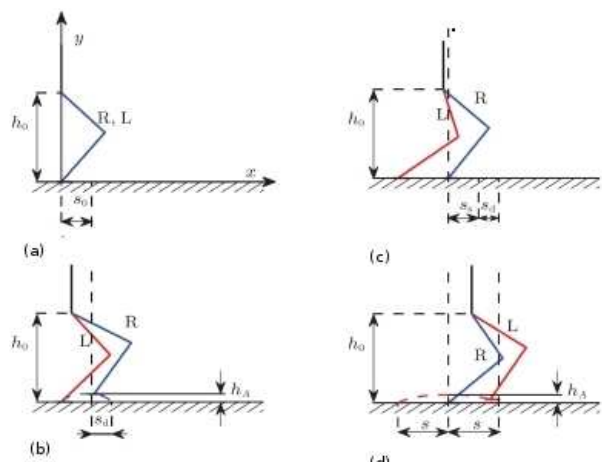

Рис. 1 - Фази руху крокуючого апарата. а. - початкова фаза; b. - фаза першого кроку с. - двоопорна фаза $\mathrm{d}$ - одноопорна фраза

Після цього знову настає фаза двохопорної, але вже динамічної стійкості (рис. 1, с), що супроводжуеться переносом центру мас АКА, для якої характерна зміна величини сили реакції в опорах.

Узагальнена модель руху АКА, як твердого багатоланкового тіла, описуеться системою [7]:

$$
M(y) \ddot{y}=h(\dot{y}, y)+B^{T} \tau
$$

де $M(y) \in R^{(n \times k)}$ - матриця просторового положення апарата ( $n$ кількість ступенів свободи; $k$ - кількість ланок у складі АКА); $y=$ $\left[y_{1}, y_{2}, \ldots, y_{n}\right]^{T}$ - вектор стану системи; $h(\dot{y}, y)$ - зовнішні сили, що діють на AKA; $B^{T}$ - матриця керованих впливів; $\tau$ - моменти в шарнірах. 
Зауважуючи на те, що під час руху АКА контактуе з ПП у певних точках, які накладають на рух його ланок обмеження, кількість яких варіюеться від $m$ (для $\mathrm{OC}$ ) до $2 m$ (для ДС), то в загальному випадку, кількість ступенів свободи АКА буде лежати в діапазоні від $k=n-m$ до $l-n-2 m$.

Виділимо наступні основні групи обмежень, які описують всі можливі безударні фрази руху АКА:

I група - реономні обмеження, які діють на АКА у випадку, якщо $l-n-2 m$;

II група - альтернативні, які можуть бути:

кутові (для випадку OC), коли параметри лівої опори (L) обмежені реономними параметрами $m$;

голономні (для випадку ДС), коли обмеження діють на розвантажену опору дотичну до ПП;

III група - скеленомні обмеження, які діють на навантажену опору (у випадку ОС) або на розвантажену опору (у випадку ДС).

Означені вище обмеження є основними і можуть бути представлені у вигляді наступного рівняння:

$$
\varphi=\min \left[\varphi_{a}^{T}, \varphi_{b}^{T}, \varphi_{c}^{T},\right]^{T}=0,
$$

де - найменша з диференціальних фрункцій; $\varphi_{a}, \varphi_{b}, \varphi_{c}$ - вектори розмірності $l, m, k$ відповідно. Тоді, рівняння керування рухом АКА буде мати наступний вигляд:

$$
\begin{gathered}
M \ddot{y}=h+B^{\tau}+C_{b}^{T} \lambda_{b}+C_{c}^{T} \lambda_{c}, \\
C_{c}(\dot{y}, y, t) \ddot{y}+C_{c 0}(\dot{Y}, y, t)=0,
\end{gathered}
$$

де $\lambda_{b}=\left[\lambda_{b 1}, \lambda_{b 2}, \ldots, \lambda_{b m}\right]^{T}$ - обумовлена реакція на обмеження II гурпи; $B^{\tau}$ - матриця керуючих впливів за моментами; $C_{c}^{T} \lambda_{c}$ - обумовлена реакція на обмеження III гурпи; $\lambda_{c}$ - узагальнені обмеження, накладені на дотичну до поверхні ланку АКА; $\left[C_{b}\right]^{T}=\left[\frac{d \varphi_{b}}{d y}\right]^{T} \mathrm{i}\left[C_{c}\right]^{T}=\left[\frac{d \varphi_{c}}{d y}\right]^{T}-$ зміні моментів у шарнірах.

У фазі ДС наявність $m$ дотичних до ПП точок накладає відповідні додаткові обмеження на переміщення АКА. Дані обмеження формуються у результаті дії відповідних $m$ сил реакцій опори. Величина сили реакції розвантаженої опори АКА для випадку ДС становитиме $\lambda_{b}$, a при переході від фрази ДС до фази ОС наближатиметься до нуля. Таким чином, опора взаємодіє з ПП без будь яких зіткнень.

Для визначення кутового моменту $\tau$, з $n$ рівнянь (3) отримаємо $n-m$ взаємозамінних рівнянь шляхом перемноження лівих частин рівнянь (3) на ортогональну матрицю доповнень $D_{c}$. Таким чином, $D_{c} C_{c}^{T}=0$, де $D_{c}$ має розмірність $(n-m) \times n$, а останній член рівняння (3) - скорочуеться. Тоді, значення кутового моменту визначається умовою: 


$$
\tau=\left(D_{c} B^{T}\right)^{-1} D_{c}\left(M \ddot{y}-h-C_{b}^{T} \lambda_{b}\right),
$$

а обмеження, накладені реакцією опори, можна описати так:

$$
\begin{gathered}
\lambda_{c}(\dot{y}, y, t)=-\left(C_{c} M^{-1} C_{c}^{T}\right)^{-1}\left[C_{c 0}+C_{c} M^{-1}\left(h+B^{T} \tau+C_{b}^{T} \lambda_{b}\right)\right] \\
C_{c 0}(\dot{y}, y, t)=-\left[\dot{C}_{c} \dot{y}+d / d t\left(d \varphi_{c} / d t\right)\right] .
\end{gathered}
$$

Модель (6) наведена без врахування маси АКА та його тертя з поверхнею. Крім того, дана модель змінюе вектор стану системи, який визначаеться залежністю $y=\left[x_{H}, y_{H}, \Theta_{R 1}, \Theta_{R 2}, \Theta_{R 3}, \Theta_{L 1}, \Theta_{L 2}, \Theta_{L 3}, \Theta_{T}\right]^{T}, k=6$, $m=3, l=3$, де параметри рівняння вказані згідно рисунка 2 .

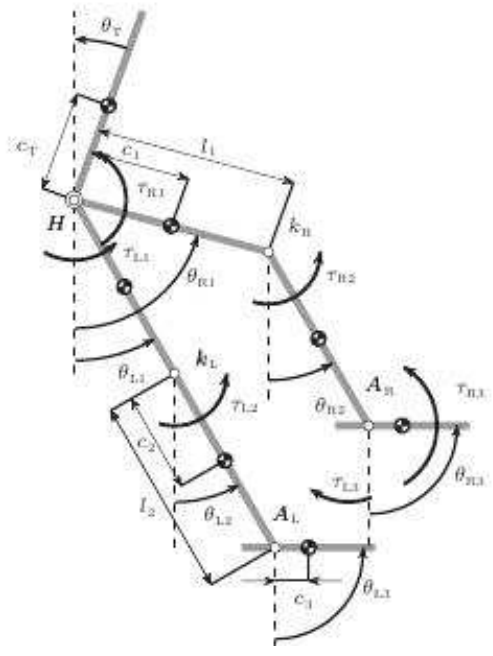

Рис. 2 - Схема зв'язків ланок, моменів у шарнірах та кутів між ланками AKA

Обмеження I групи задають траєкторію руху ланки $C_{1}$ (рис. 2 ) та положення корпуса АКА. У загальному випадку їх можна описати так:

$$
\varphi_{a}=\left[x_{H}-x_{H \tan _{n}}(t) ; y_{h}=\left(h_{0}-x_{H} \tan \gamma\right) ; \Theta_{T}\right]=0
$$

Тоді, обмеження II та III груп можуть бути подані у вигляді:

$$
\varphi_{b, c}=\left[\begin{array}{l}
x_{H}+l_{1} \sin \theta_{i 1}+l_{2} \sin \theta_{i 2}-x_{A i} ; \\
y_{H}-l_{1} \cos \theta_{i 1}-l_{2} \cos \theta_{i 2}-y_{A i} ; \theta_{i 3}-(\pi / 2+\gamma)
\end{array}\right]=0
$$

де і визначає $\mathrm{R}$ або $\mathrm{L} ; x_{A i}$ i $y_{A i}$ - координати ланки $C_{1}$ (рис. 2 ); $\gamma$ - градієнт нахилу ПП (додатній у випадку підйому та від'ємним для випадку спуску); $\theta_{i}$ - кут нахилу ланок АКА до вектору гравітації (рис. 2); $l_{1}, l_{2}$ 
- довжини ланок АКА (рис. 2). При цьому кількість обмежень $n=3$ і $m=3$ для кожної ланки і $l=3$ для корпуса.

Координати ланки $C_{1}$ для першого кроку визначаються з рівняння $x_{H n}(t)=a_{5} t^{5}+a_{4} t^{4}+a_{3} t^{3}$ з врахуванням градієнтних обмежень $x_{H n}(0)=$ $\dot{x}_{H n}(0)=\ddot{x}_{H n}\left(T_{0}\right), x_{H n}\left(t_{0}\right)=s_{0}, \dot{x}_{H n}\left(t_{0}\right)=v_{0}$ i $\ddot{x}_{H n}\left(T_{0}\right)=0 ; T_{0}$ i $s_{0}-$ періоди і довжина першого кроку. Для всіх наступних кроків швидкість переміщення ланки $C_{1}$ (рис. 2) $v_{0}$ постійна і подана у виді $x_{H n}(t)=s_{0}+$ $v_{0}\left(t-T_{0}\right)$, де $T_{0}=T_{s s}+T_{d s}, s_{d}=v_{0} T_{D S}$ i $s_{s}=v_{0} T_{s s}, T_{D S}$ i $T_{S S}-$ період ДС і ОС фаз - відповідно. Наступні фрази руху АКА описуються аналогічно.

У випадках голономних та скеленомних обмежень $x_{A i}$ буде константою, відмінною від нуля, а $y_{A i}=0$. Для реономних обмежень, положення ланки $C_{1}$ по осі Х визначаеться виразом $x_{A i n}(t)=b_{5} t^{5}+b_{4} t^{4}+b_{3} t^{3}+$ $b_{2} t^{2}+b_{1} t+b_{0}$. Коефіцієнти в даному виразі вибираються таким чином, щоб задовольнити умови:

$$
\begin{aligned}
& x_{A i n}\left(T_{s s 1}\right)=0 ; \\
& z<3 ; \\
& x_{A i n}\left(T_{s s 1}\right)=(z-2) s ; \\
& \dot{x}_{A i n}\left(T_{s s 1}\right)=\ddot{x}_{A i n}\left(T_{s s 1}\right)=0 ; \\
& a_{A i n}\left(T_{s s 3}\right)=z s ; \\
& \dot{x}_{A i n}\left(T_{s s 3}\right)=\ddot{x}_{A i n}\left(T_{s s 3}\right)=0,
\end{aligned}
$$

де $\mathrm{z}$ - номер поточного кроку, $T_{s s 1}$ - час від початку поточної ОС фрази, для якої виконуеться умова $T_{s s 3}=T_{s s 1}+T_{s s}$.

Координати ланки $C_{3}$ (рис. 2) по осі $\mathrm{X}$ можуть бути отримані з рівняння $x_{A i}=x_{A \text { in }}(t)$.

Фаза двоопорної динамічної стійкості складіається з двох складових. Перша складова задається рівнянням

$y_{\text {Ain }}(t)=c_{5} t^{5}+c_{4} t^{4}+c_{3} t^{3}+c_{2} t^{2}+c_{1} t+c_{0}$, за умови виконання рівнянь:

$$
\begin{aligned}
& y_{A i n 1}\left(T_{s s 1}\right)=\dot{y}_{A i n 1}\left(T_{s s 1}\right)+\ddot{y}_{A i n 1}\left(T_{s s 1}\right)=0, y_{A i n 1}\left(T_{s s 2}\right)=h_{A} \\
& \dot{y}_{A i n 1}\left(T_{s s 2}\right)=\ddot{y}_{A i n 1}(T s s 2)=0 .
\end{aligned}
$$

де $T_{s s 2}=T_{s s 1}+0.5 T_{s s}-$ час у середині поточного кроку.

Тоді друга складова визначається рівнянням:

$y_{\text {Ain2 } 2}(t)=d_{5} t^{5}+d_{4} t^{4}+d_{3} t^{3}+d_{2} t^{2}+d_{1} t+d_{0}$, при умові виконання рівнянь:

$y_{A o m 2}\left(T_{s s 2}\right)=h_{A}, \dot{y}_{A i n 2}\left(T_{s s 2}\right)=\ddot{y}_{A i n 2}\left(T_{s s 2}\right)=0$;

$T_{A i}\left(T_{s s 3}\right)=\dot{y}_{A i n 2}\left(T_{s s 3}\right)=\ddot{y}_{A i n 2}\left(T_{s s 3}\right)=0$.

Координати ланки $C_{3}$ (рис. 2 ) по напряму Y отримуеться з рівняння:

$$
\begin{aligned}
& y_{A i}=y_{A i n 1}(t)+x_{A i n}(t) \tan \gamma, t \in\left[T_{s s 1}, T_{s s 2}\right] \\
& y_{A i}=y_{A i n 2}(t)+x_{A i n}(t) \tan \gamma, t \in\left[T_{s s 2}, T_{s s 3}\right]
\end{aligned}
$$

Тоді, матриці $C_{c}$

і $D_{c}$ для рівнянь $(5,6)$ визначаються з рівняння $(9)$ у вигляді:

$$
C_{c}=\begin{array}{ccccccccc}
1 & 0 & l_{1} \cos \theta R 1 & l_{2} \cos \theta R 2 & 0 & 0 & 0 & 0 & 0 \\
0 & 1 & l_{1} \sin \theta R 2 & l_{2} \sin \theta R 2 & 0 & 0 & 0 & 0 & 0 \\
0 & 0 & 0 & 0 & 1 & 0 & 0 & 0 & 0
\end{array}
$$




$$
D_{c}=\begin{array}{ccccccccc}
-l_{1} \cos \theta_{R 1} & -l_{1} \sin \theta_{R 1} & 1 & 0 & 0 & 0 & 0 & 0 & 0 \\
-l_{2} \cos \theta_{R 2} & -l_{2} \sin \theta_{R 2} & 0 & 1 & 0 & 0 & 0 & 0 & 0 \\
0 & 0 & 0 & 0 & 0 & 1 & 0 & 0 & 0 \\
0 & 0 & 0 & 0 & 0 & 0 & 1 & 0 & 0 \\
0 & 0 & 0 & 0 & 0 & 0 & 0 & 1 & 0 \\
0 & 0 & 0 & 0 & 0 & 0 & 0 & 0 & 1
\end{array}
$$

Рівняння $(10,11)$ дійсні при наявності обмежень III групи, що накладені на закон переміщення правої опори АКА (R), тобто для випадку, коли права опора АКА дотикаеться до поверхні у фразах руху ДС і ОС. У іншому випадку, коли ліва опора (L) дотикається до поверхні, стовпці 3-5 і 6-8 рівнянь $(10,11)$ взаємно замінюються. Окрім того, очевидно, що у випадку голономних обмежень, накладених на опору L, здійснюеться модифікація матриці $C_{c}$ до виду:

$$
C_{c}=\begin{array}{ccccccccc}
1 & 0 & 0 & 0 & 0 & l_{1} \cos \theta L 1 & l_{2} \cos \theta L 2 & 0 & 0 \\
0 & 1 & 0 & 0 & 0 & l_{1} \sin \theta L 1 & l_{2} \sin \theta L 2 & 0 & 0 \\
0 & 0 & 0 & 0 & 0 & 0 & 0 & 1 & 0
\end{array}
$$

$\mathrm{y}$ випадку накладення тих же обмежень на опору $\mathrm{R}$ виконуються відповідні зміни у рівнянні 11 до виду рівняння 12 .

Обмеження довілної поверхні на переміщення опор $\mathrm{L}$ та $\mathrm{R}$ задаються у вигляді $\lambda_{b n}(t)=\left(\lambda_{b 0} / 2\right)\left[1+\cos \left(\pi t / T_{D S}\right)\right]$. Параметри $\lambda_{b}=$ $\left[F_{b i T}, F_{b i N}, M_{b i}\right]^{T}, i=R, L$ показані на рис. 3 , де $F_{b i N}$ і $F_{b i T}$

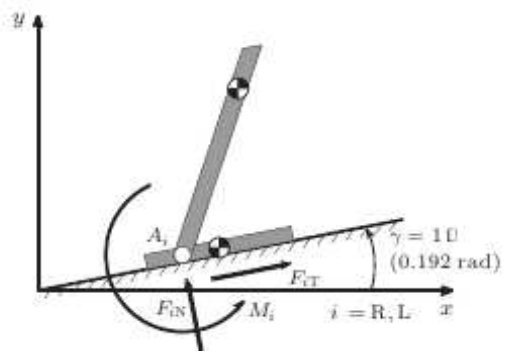

Рис. 3 - Параметричні обмеження довільної поверхні на переміщення ланки $C_{3}$

Тоді, якщо $\lambda_{b 0}$ містить значення реакції опори на початку фази ДС, то $t$ - задає фактичний час фази руху.

Значення сили реакції опори у випадку обмежень III групи визначатиметься з рівнянь 6 у вигляді: $\lambda_{c}=\left[F_{c i T}, F_{c i N}, M_{c i}\right]^{T}, i=R, L$, де $F_{c i N}$ і $F_{c i T} \in$ такими ж реакціями, що і у випадку наведеному раніше у обчисленнях.

Траєкторії ланок $C_{1}, C_{2}, C_{3}$ (рис. 2), описаних рівнянням (8), задається параметрами вектора стану апарата:, $s_{0}=s_{s}=0.12 \mathrm{~m}, s=s_{d}=02 \mathrm{~m}$, 
$v_{0}=0.4 \mathrm{~m} / \mathrm{s}, T_{0}=0.5 \mathrm{~s}, h_{0}=0.55 \mathrm{~m}, h_{A}=0.05 \mathrm{~m}$, згідно з даними в таблиці 1.

Параметри конструкції досліджуваного АКА

\begin{tabular}{|l|l|l|l|}
\hline параметри & 1 ланка $\left(C_{1}\right)$ & 2 ланка $\left(C_{2}\right)$ & 3 ланка $\left(C_{3}\right)$ \\
\hline$m_{j}$ & $5 \mathrm{~kg}$ & $2.25 \mathrm{~kg}$ & $0.5 \mathrm{~kg}$ \\
\hline$J_{j}$ & $0.1 \mathrm{~kg} * \mathrm{~m} 2$ & $0.1 \mathrm{~kg} * \mathrm{~m} 2$ & $0.006 \mathrm{~kg} * \mathrm{~m} 2$ \\
\hline$l_{j}$ & 0.3 & $0.35 \mathrm{~m}$ & - \\
\hline$c_{j}$ & 0.07 & $0.15 \mathrm{~m}$ & $0.05 \mathrm{~m}$ \\
\hline$m_{T}$ & 15 & - & - \\
\hline$J_{T}$ & 1 & - & - \\
\hline$c_{T}$ & $0.2 \mathrm{~m}$ & - & - \\
\hline
\end{tabular}

Координати положення ланок визначаються за допомогою дев'яти нелінійних алгебраїчних рівнянь (2) та метода чисельної ітерації.

Похідні координат положення АКА отримують з диференційної форми рівняння 2. Після визначення диференційної форми визначаються обмеження, що некладені на ланки. Потім визначаеться значення кутового моменту та сили реакції опори, визначаються шляхом вирішення алгебраїчних рівнянь 5, 6 - відповідно. В результаті отримаємо формалізацію АКА для випадків $a-d$ фаз руху (рис. 1).

Було проведено експеримент переміщення АКА трьома типами поверхонь по п'ять кроків на кожній. Перша поверхня мала схил на $10^{\circ}$ у площині рискання, друга поверхня - без зміни висоти, а третя поверхня з підйомом на $10^{\circ}$. На рис. 4 показано зміщення ланки $C_{3}$ (рис. 2) для випадку трьох типів ПП у сагітальній площині.
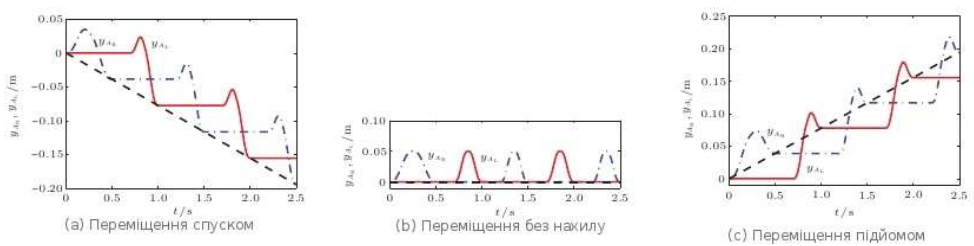

Рис. 4 - Переміщення ланки $C_{3}$ у випадках руху спуском (а), прямою площиною (b) та підйомом (c)

На рис. 5 зображено керування АКА за моментом і силою реакції опори, з якої видно, що максимальне значення моментів у шарнірах досягаеться під час підйому похилою площиною, тоді, як рух без нахилу та спуск мають мінімальні значення моментів, що свідчить про їх низьку енергоємність, зокрема для ОС фази руху.

Зважаючи на те, що кінематична енергія еквівалента сумі робіт по їі переміщенню та дотриманню рівноваги, робота приводів АКА може бути розрахована так: 


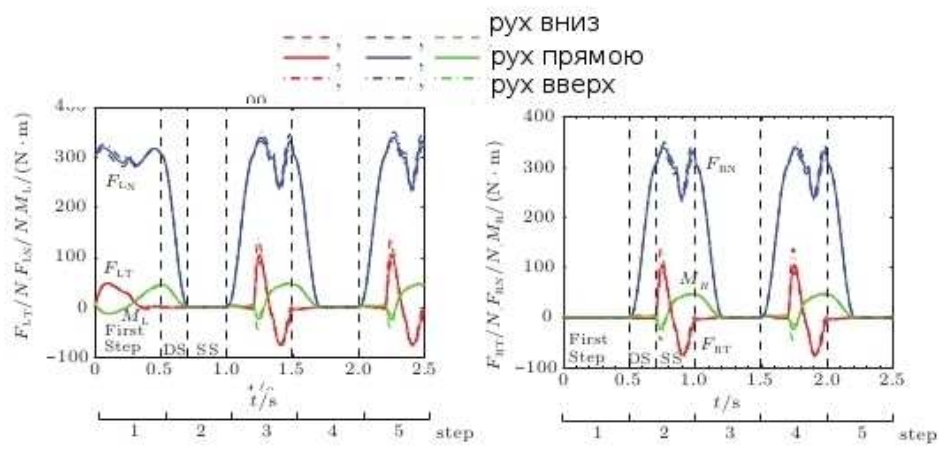

Рис. 5 - Керування лівою та правою опорами за моментом та силою в опорі

$$
W(t)=\int\left|u_{m} \omega\right| d t,\left[t_{0}, t_{1}\right],
$$

де $u_{m}=\left[\tau_{R 1}+\tau_{R 2}+\tau_{R 3}+\tau_{L 1}+\tau_{L 2}+\tau_{L 3}\right]-$ вектор відносних кутових швидкостей у шарнірах; $\left[t_{0}, t_{1}\right]$ - інтервал часу на один крок.

Тоді, загальні енергетичні витрати на один крок АКА визначаються так: $W_{\text {total }}(t)=R_{R 1}(t)+R_{R 2}(t)+R_{R 3}(t)+R_{L 1}(t)+R_{L 2}(t)+R_{L 3}(t)$.

Параметр $P=\left|u_{m} \omega\right|$ є механічною потужністю, яка не потребує едективної роботи приводів та здійснюеться засобами пасивної динаміки, а енергетичні затрати на активному етапі переміщення АКА незалежні від поверхні, що проілюстровано на рис. 6.

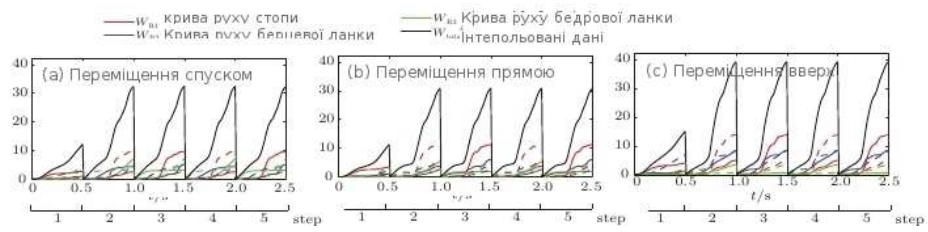

Рис. 6 - Енергетичні затрати на ефективному етапі руху у випадках спуску, переміщення та підйомом - відповідно

\section{Висновки}

Проведені в роботі дослідження показали, що використання пасивної динаміки для забезпечення руху АКА $є$ більш енергоефективними ніж активної динаміки, та при цьому забезпечує дотримання динамічної рівноваги під час руху АКА на довільній поверхні. 


\section{Література}

1. W. Blajer, and W. Schiehlen, ASME, J. Dyn. Sys., Measur. Control 114, 660 (1992). P. 30-42.

2. Задачи управления шагающими аппаратами / Бордюг Б.А., Ларин В.Б., Тимошенко А.Г. - Киев : Наук. Думка, 1985. - С 52-60.

3. . Gruber, and W. Schiehlen, in: Proceedings of the Thirteenth CISMIFToMM Symposium (Springer-Verlag, Wien, 2000). P. 433-433.

4. L. Yang, C. Chew, and T. Zielinska, et al., Robotica 25, 549 (2007). P. 14-18.

5. Daberkow, J. Gao, and W. Schiehlen, in: Proceedings of the Eight CISMIFToMM Symposium (Warsaw University of Technology, Warsaw, 1990). P. 2-

6. S. Gruber, and W. Schiehlen, in: Proceedings of Euromech 375, Biology and Technology of Walking (Lehrstuhl B fuer Mechanik, Technische Universitaet Muenchen, Muenchen, 1998). P. 1-3.

7. D. J. Braun, and M. Goldfarb, IEEE Trans. Robot. 25, 1292 (2009). P. $22-42$.

Отримано 10.12.2012 p. 